\title{
Corrigendum to "Genetic Diagnosis of Charcot-Marie-Tooth Disease in a Population by Next-Generation Sequencing"
}

\author{
Helle Høyer, ${ }^{1,2,3}$ Geir J. Braathen, ${ }^{1,2,3}$ Øyvind L. Busk, ${ }^{1}$ \\ Øystein L. Holla, ${ }^{1}$ Marit Svendsen, ${ }^{1}$ Hilde T. Hilmarsen, ${ }^{1}$ Linda Strand, ${ }^{1}$ \\ Camilla F. Skjelbred, ${ }^{1}$ and Michael B. Russell ${ }^{2,3}$ \\ ${ }^{1}$ Section of Medical Genetics, Department of Laboratory Medicine, Telemark Hospital, 3710 Skien, Norway \\ ${ }^{2}$ Head and Neck Research Group, Research Centre, Akershus University Hospital, Lørenskog, Norway \\ ${ }^{3}$ Campus Akershus University Hospital, University of Oslo, Nordbyhagen, Norway
}

Correspondence should be addressed to Helle Høyer; helle.hoyer@sthf.no

Received 8 September 2015; Accepted 21 September 2015

Copyright @ 2015 Helle Høyer et al. This is an open access article distributed under the Creative Commons Attribution License, which permits unrestricted use, distribution, and reproduction in any medium, provided the original work is properly cited.

In Table 4 and Supplemental Table 1 of the published paper entitled "Genetic Diagnosis of Charcot-Marie-Tooth Disease in a Population by Next-Generation Sequencing" [1], we classified two variants as likely pathogenic. These two variants (NM_001126131.1:c.[1491G>C(;)2243G>C]), identified in the $P O L G$ gene, were carried by one patient (ID 62). As it was not possible to examine whether the two variants were in cis or trans, that is, situated on the same or different alleles, these two variants should have been reported as uncertain pathogenic variants.

This change also influences the Results, where the prevalence of identified variants is corrected to 8 likely and 17 uncertain pathogenic variants.

In Figure 1, the number of families with likely pathogenic variants is reduced to $n=7(9 \%)$ and the number for families with uncertain pathogenic variants is increased to $n=10(12 \%)$. And in Figure 2(b), the number of CMT2 families in the category "other point mutations" is reduced to $n=7(21 \%)$ and the number of families with uncertain pathogenic variants is increased to $n=5(15 \%)$. See corrected Figures 1 and 2(b).

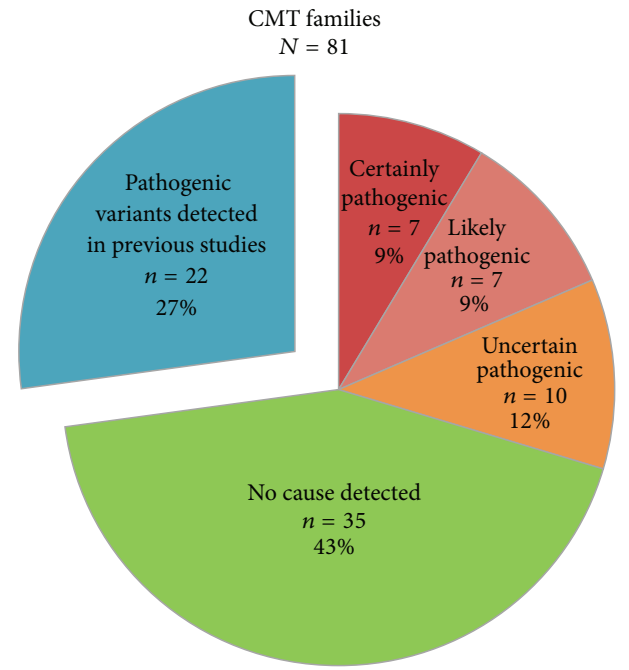

FIGURE 1: Identified variants in 81 Norwegian CMT families from the general population. Our previous studies identified copy-number variations in $12 \mathrm{CMT}$ families and pathogenic point mutations in 10 CMT families $[2,14,19]$. The remaining 59 CMT families were investigated by next-generation sequencing. 


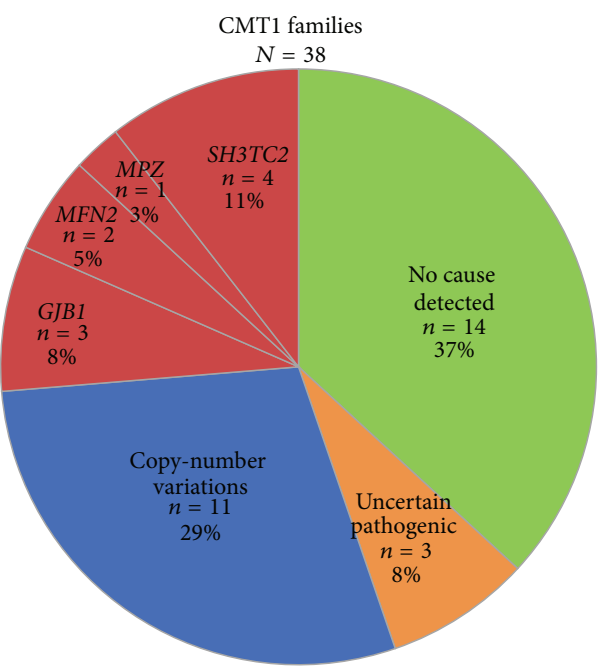

(a)

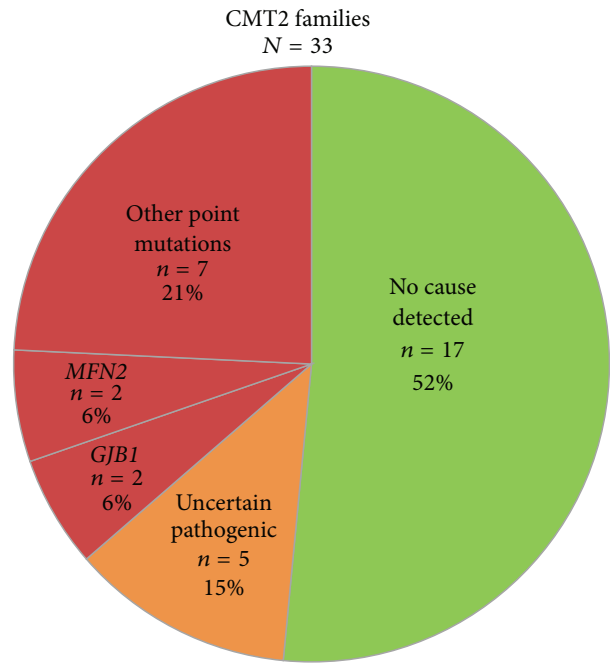

(b)

FIGURE 2: Frequencies of certain and likely pathogenic variants in CMT1 and CMT2 families from the Norwegian general population.

\section{References}

[1] H. Høyer, G. J. Braathen, Ø. L. Busk et al., "Genetic diagnosis of Charcot-Marie-Tooth disease in a population by nextgeneration sequencing," BioMed Research International, vol. 2014, Article ID 210401, 13 pages, 2014. 

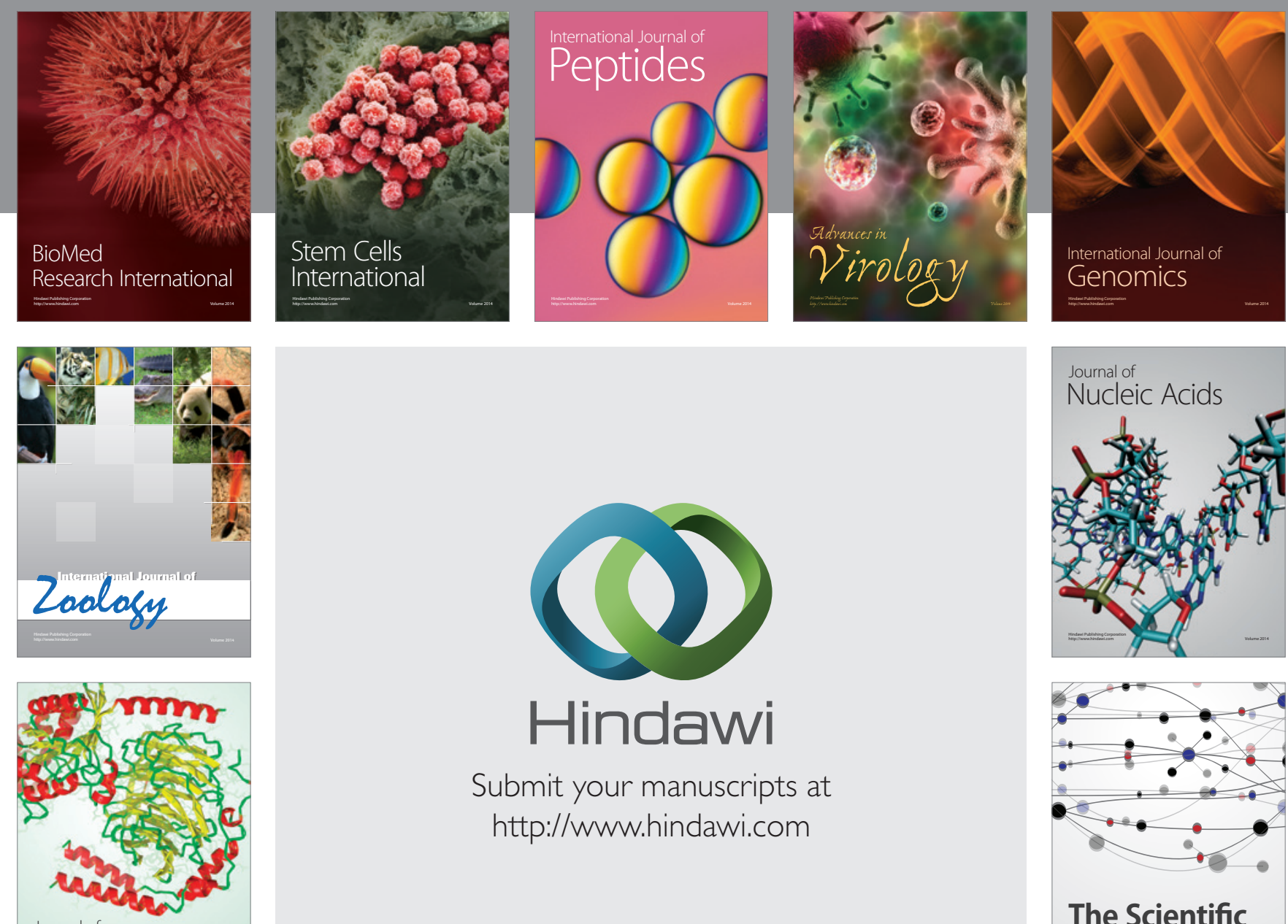

Submit your manuscripts at

http://www.hindawi.com

Journal of
Signal Transduction
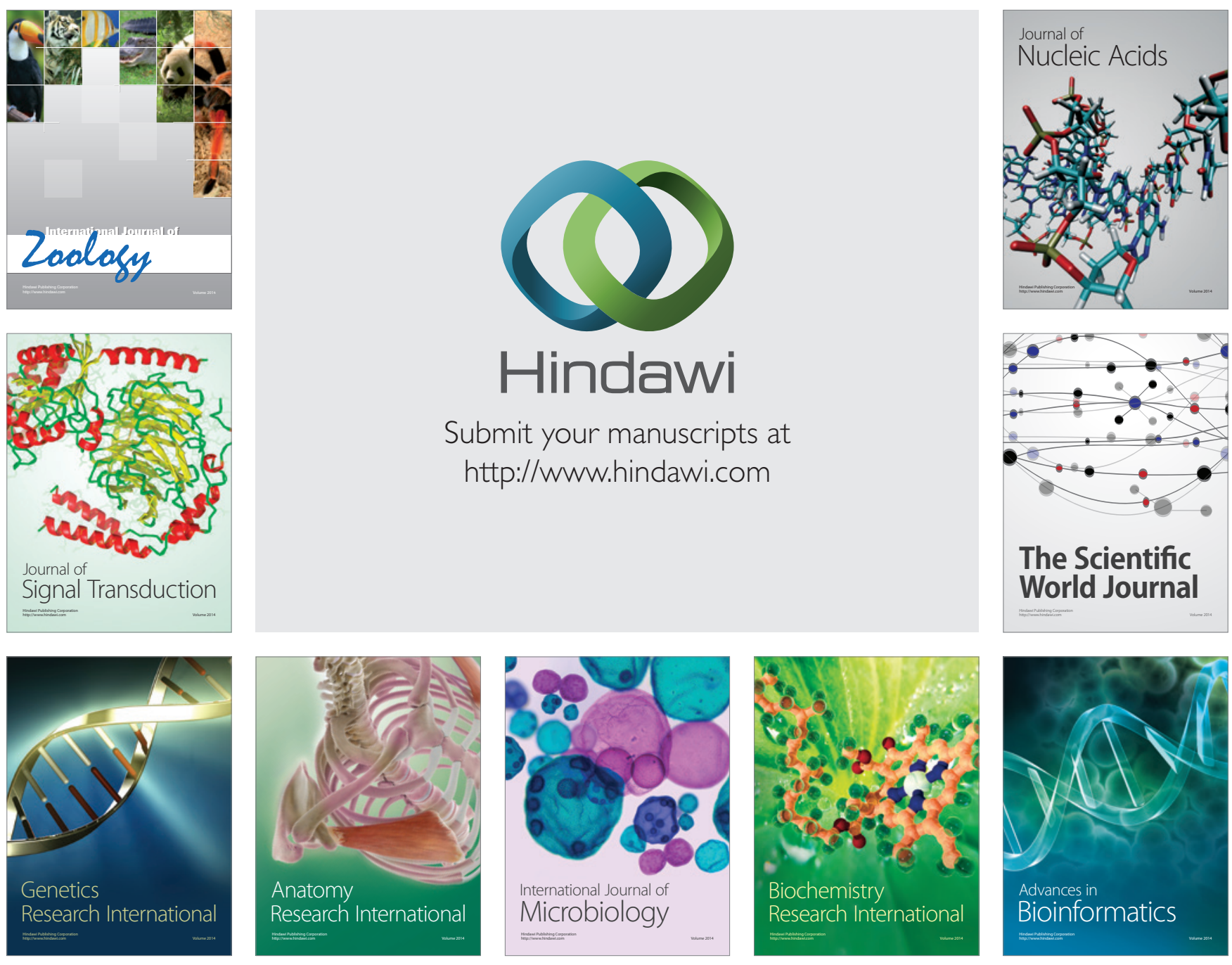

The Scientific World Journal
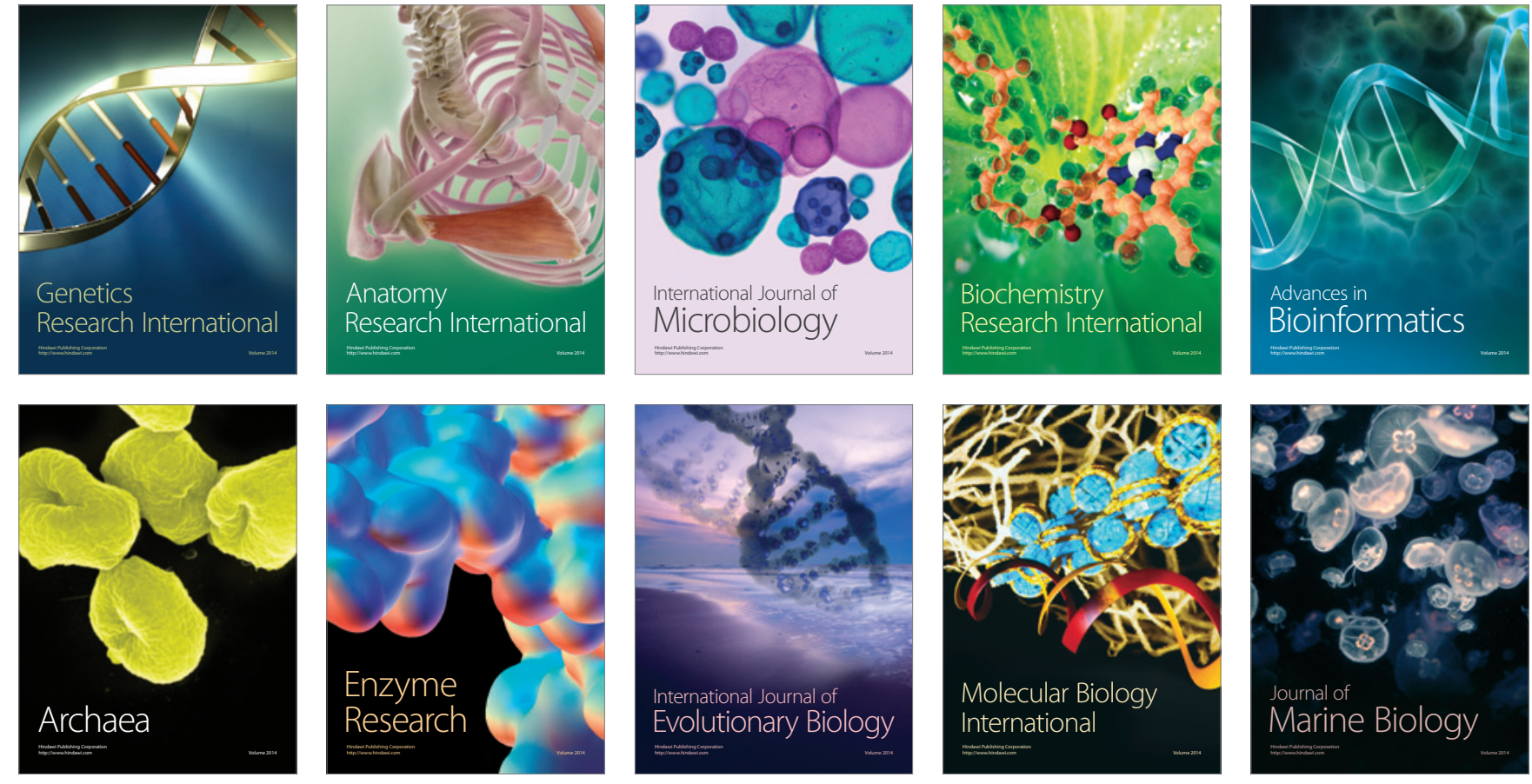